\title{
Research on the Third-Person Effect of Online Commercial Advertisements - Based on the Students from Guangzhou Huashang College
}

\begin{abstract}
Xianfeng Gong, Lingwei Chu*
Department of Communication and Media, Guangzhou Huashang College, Guangzhou 511300, Guangdong Province, China

*Corresponding author: Lingwei Chu, riwei993799@163.com

Abstract: The third-person effect hypothesis has become one of the most important aspects in the research field within the American empirical school. A large number of studies have adopted empirical research methods to verify the reliability of the third-person effect. With the rise of the network society, local research on the third-person effect has gradually extended to the verification or falsification of the third-person effect in the network environment. This article begins with a study on the third-person effect of online commercial advertisements based on the students from Guangzhou Huashang College. Through the study, the research hypotheses have been proposed and questionnaires have been distributed to the research subjects for analysis. Based on a series of quantitative operations, such as data analysis, empirical observations, and empirical research, this study provides a source of reference and reflection for research in this field.
\end{abstract}

Keywords: Online commercial advertising; Third-person effect

Publication date: December 2021; Online publication: December 31, 2021

\section{Research question}

The third-person effect hypothesis was originally proposed by Phillips Davidson, a Professor of Journalism and Sociology at Columbia University. Davidson proved the hypothesis through four experiments. He mentioned, "The recipients of persuasion communication will think that this persuasion has a greater impact on others than on themselves. Moreover, regardless of the directness of the message, the anticipation of the effect of the media on others will cause the audience to take certain actions. Any communication effect is not attributed to the reaction of the direct audience, as it is from the behavior of those who anticipate or think they have observed the reaction of others ${ }^{[1]}$." Specifically, there are two levels: the first is the cognitive level, where people tend to highly evaluate the impact of mass communication on others, while underestimating the impact on themselves, or the coexistence of both estimates, especially in dealing with negative contents ${ }^{[2]}$; the second is the action level, where people's expectations of the possible influence of mass media on others will lead them to take corresponding actions, such as the support for media content review. After Davidson proposed the third-person effect hypothesis, a large number of studies have adopted empirical research methods to verify the reliable existence of the third-person effect ${ }^{[3]}$.

With the rise and development of the internet, online advertisements, especially commercial advertisements, are all over the internet in various forms, such as texts, pictures, and videos. They have become increasingly important forms of advertising. At present, the research on the effect of online advertising mostly focuses on its direct effects, neglecting the indirect effects of online advertising and the subsequent behavioral reactions that it may cause. 
For advertising communication, in addition to the direct effects, the audience's response to advertising information and behavioral intentions may be derived from the perception that the advertisement affects others; that is, through an indirect effect model. In the internet age, how do audiences view the impact of online advertising on themselves and others, and how does this perception affect the effect of online advertising? The third-person effect hypothesis provides a research perspective to understand the indirect effects of online advertising.

In recent years, local research on the third-person effect has gradually extended to the verification or falsification of the third-person effect in the network environment. Foreign research mainly focuses on the third-person effect of online pornographic information. However, there are some studies that have analyzed the third-person effect of online information, such as violence, online advertising, and online games. Except for a few domestic studies that have explored the third-person effect of online pornographic information and online rumors, the research on the third-person effect of online advertising, online games, and other online information is basically in a blank state.

Based on the current research status at home and abroad, this study intends to take online commercial advertising as the research subject to discuss the third-person cognition and follow-up behavior of online commercial advertising. In the new virtual communication context created by the internet, the focus is on whether the third-person effect of online commercial advertising exists. If so, what are the influencing factors? This research conducts a localized test of the relevant hypotheses about the effect of third parties in the context of online commercial advertising ${ }^{[4]}$.

\section{Research hypothesis}

According to existing research and theoretical explanations of the third-person effect, it is expected that there is a third-person effect (including cognitive and behavioral aspects) in online commercial advertisements. The influencing factors put forward in previous research are also possible factors that affect the third-person effect of online commercial advertising. Therefore, for the third-person effect of online commercial advertising, the basic assumptions of this research are as follows:

(1) for online commercials, there is a third-person effect, where people tend to think that online commercials affect others more than themselves;

(2) the influencing factors of the third-person cognition of online commercial advertising include social demographic variables, media use, social distance, information characteristics (information credibility, social recognition, and persuasive characteristics), personal characteristics, and other existing ones;

(3) the third-person effect perception of online commercial advertising is the main influencing factor supporting the restriction of online commercial advertising; that is to say, the third-person perception of online commercial advertising will lead to the support of the subsequent behavior of restricting online commercial advertising;

(4) social demographic variables, information characteristics, media use, perceived influence on oneself, perceived influence on others, expectations of the behavior of others, etc. are also possible factors influencing the subsequent behavior of the third person in online commercial advertising (supporting the restrictions in online commercial advertising) ${ }^{[5]}$.

Based on the above four research hypotheses, four more hypotheses have been proposed.

(1) Hypothesis 1: For online commercial advertising, there is a third-person effect; that is, people tend to recognize that the impact of online commercials on others is greater than the impact on oneself. 
(2) Hypothesis 2: Gender, professional background, types of media contact, purpose of media use, internet age, average daily online time, internet efficacy, social recognition of online commercial advertisements, credibility of online commercial advertisements, audience's pre-existing attitude toward online commercial advertisements, audience's overall evaluation of online commercial advertisements, self-esteem, etc. have significant correlations with the third-person effect perception of online commercial advertising.

(3) Hypothesis 3: The awareness of the third-person effect of online commercial advertising and the support for restricting internet commercial advertising have a significant positive correlation between them.

(4) Hypothesis 4: There is a positive correlation between other factors and the attitude that support the restriction of online commercial advertising, including demographic variables, perceived influence on oneself, perceived influence on others, expectations of the behavior of others, information desirability, information credibility, pre-existing attitude, social distance, media use, etc.

\section{Research methods}

This research adopts empirical research methods; specifically, two research methods have been adopted: questionnaire survey and experimental research. These two methods are the most commonly used research methods in previous third-person effect research.

\subsection{Participants and questionnaire distribution}

In this study, 200 science, engineering, and art undergraduates from Guangzhou Huashang College were recruited as the research subjects. They are of the Chinese nationality. On a class basis, the questionnaires were distributed to the students in the classroom, and the students were asked to fill in their answers. A total of 554 valid questionnaires were recovered.

A small-scale pre-testing was conducted using the questionnaire before it was officially released. The format, wording, and question design were adjusted according to the results of the pre-test to ensure that the respondents could understand the meaning of the questions and scales in the questionnaire. In addition, the respondents' feedback on the length of the questionnaire and the difficulty in completing the questionnaire were also taken into account in the adjustment process.

\subsection{Main variables and measurements}

(1) The main demographic variable is gender; it is divided into male and female.

(2) The professional background of the participants can be divided into three categories: liberal arts, science and engineering, as well as art.

(3) The media use includes the type of media contact, the purpose of media use, media exposure, internet age, and average daily online time. Among them, the type of media contact measures the most frequently contacted media by the respondents, which includes two options: "internet" and "non-internet." The variable of "purpose of media use" includes two options: "obtaining information" and "entertainment and relaxation." Regarding the media exposure to online commercial advertisements, the frequency of exposure to online commercial advertisements of the respondents was measured using a five-level scale from low to high: "never," "occasionally," 
"general," "frequent," and "always." In addition, internet age and average daily online time were also measured separately.

(4) The self-efficacy of internet use of the respondents was measured using a scale modified based on the internet self-efficacy scale developed by Eastin and LaRose in $2000{ }^{[6]}$. The respondents were asked to evaluate their own perceptions of "receiving emails," "searching for internet information," and "from the internet." The proficiency of the respondents in several skills, such as downloading materials from the internet and understanding network terms, was classified from low to high: "not at all," "not very proficient," "average," "relatively proficient," and "very proficient." The reliability of the scale was tested and the reliability coefficient, Cronbach's alpha was 0.865 .

(5) The credibility of online advertising was based on the respondents' evaluation of the overall credibility of online commercial advertisements using a five-level scale from low to high: "completely unreliable," "not very reliable," "average credibility," and "relatively credible," and "very credible."

(6) The degree to which online commercial advertisements meet social recognition was based on the respondents' evaluation using a five-level scale from low to high: "completely inconsistent with social recognition," "not in line with social recognition," "generally in line with social recognition," "more in line with social recognition," and "fully in line with social recognition."

(7) The pre-existing attitude of the respondents toward online commercial advertising was measured; there were three options: "supportive," "neutral," and "against."

(8) The overall evaluation of online commercial advertisements was based on the respondents' overall evaluation using a semantic scale by assigning three pairs of descriptive words: "good" and "bad," "pleasant" and "unpleasant," as well as "good for people" and "bad for people." The respondents were requested to rate online commercials in the above areas, using a 7-point scale. The leftmost word represents 1 point, and the rightmost word represents 7 points. The scale was derived from relevant research on the overall attitude toward advertising. The reliability of the scale was tested, and the reliability coefficient of the scale, Cronbach's alpha was 0.847 .

(9) The third-person effect perception of online commercial advertising was measured based on the perceived impact of online commercials on oneself and the perceived impact of online commercials on others. Between them, "influence on others" can be subdivided into the influence on other adults and the influence on others. The respondents were required to assess the influence of online commercials on themselves and others. The degree of influence is represented by a score of 1 to 5, with 1 representing the lowest degree of influence, and 5 representing the highest degree of influence. The average score of the "perceived influence of online commercials on others" minus the average score of the "perceived influence of online commercials on oneself" is equal to the third-person effect perception of online commercial advertising.

(10) The support of the attitude of restricting online commercial advertising was measured based on the degree of agreement of the respondents to two statements: "online commercial advertising should be restricted" and "the government needs to strengthen the management of online commercial advertising." The degree of agreement of the respondents were measured using a fivelevel scale from low to high: "totally disagree," "disagree," "neutral," "relatively agree," and "strongly agree." The reliability test on the scale showed that Cronbach's alpha $=0.695$.

(11) In perceiving the attitude of others who support online commercial advertising, the respondents were required to perceive the expectations of the attitude of others toward the restriction of online 
commercial advertising through a question: "Do you think other people support the restriction of online commercial advertising?". The respondents were given five options: "not supportive at all," "not very supportive," "neutral," "comparatively supportive," and "fully supportive."

(12) Social distance: the subjects in this study were college students who are basically adults. Therefore, this study assumes that the social distance between "self" and "other adults" is less than that of "self" and "minors."

(13) Self-esteem was measured using the self-esteem scale developed by Rosenberg in 1979, which has also been adopted by many previous studies. The scale mainly includes 9 statements related to self-evaluation. For example, "I feel that I am a person of worth," "I take a positive attitude toward myself," "I wish I had more respect for myself," and so on. The scale has two main components: self-esteem and self-efficacy. The statement, "I take a positive attitude toward myself" is not related to the two main components; thus, the statement was removed. Therefore, the final revised scale had only 8 statements. The coefficient reliability of the final scale, Cronbach's alpha $=0.835$.

\subsection{Statistical analysis and inspection methods}

In determining the third-person effect, a paired sample T-test was used. Correlation analysis was used to determine the correlation between variables, while multiple linear regression analysis was used for the "third-person cognition" variable to determine the main influencing factors and establish the regression equation. Multilevel regression analysis was used to determine the support of the restriction of online commercial advertising. For non-continuous variables such as gender, profession, type of media contact, and purpose of media use are assumed as dummy variables for coding in correlation analysis and regression analysis.

\section{Result analysis}

\subsection{Descriptive statistics}

(1) The research subjects were undergraduates (18-22 years old) from Guangzhou Huashang College. Among them, $37 \%$ were boys and $63 \%$ were girls. In terms of professional background, science and engineering accounted for $32.9 \%$, liberal arts accounted for $35.9 \%$, and art accounted for $31.2 \%$.

(2) The most frequently contacted media channel of the respondents was the internet, with $91.8 \%$ of the selection ratio. The main purpose of the respondents in using the internet was for "entertainment and relaxation," accounting for $60.2 \%$, followed by "obtaining information," accounting for $28.9 \%$. The respondents spent an average of "2-3 hours" and " $4-5$ hours" on the internet every day, accounting for $52.3 \%$ and $33.6 \%$, respectively.

(3) In evaluating their own ability to use the internet, the average score of the respondents was 3.81, which is between "average" ( 3 points) and "relatively proficient" (4 points).

(4) In regard to their self-esteem, the negative expression of self-evaluation in the scale has been reversely assigned. The average score after the scale assignment was 3.83 , which is between "average" (3 points) and "relatively agree" (4 points).

(5) The respondents' exposure to online commercial advertisements was assigned an average score of 3.58 points, which is between "average" ( 3 points) and "frequent" ( 4 points). 
(6) In the evaluation of social recognition of online commercial advertising, the average score was 2.93 points, which is between "not very recognized" ( 2 points) and "average" ( 3 points).

(7) The average score for the respondents' evaluation of the credibility of online commercial advertisements was 2.58 , which is between "not very credible" ( 2 points) and "average" ( 3 points).

(8) The respondents' pre-existing attitude toward online commercial advertisements was assigned an average score of 2.07 points, which is between "neutral" ( 2 points) and "against" ( 3 points).

(9) The average score of the respondents' overall evaluation of online commercial advertisements was 4.14 points, which is more biased toward the extreme value of a negative evaluation (7 points).

(10) The respondents' agreement to support the restriction of online commercial advertising scored 3.73 points, which is between "neutral" ( 3 points) and "relatively agree" ( 4 points).

(11) The respondents scored an average of 3.41 points in perceiving the attitude of others in supporting the restriction of online commercial advertising, which is between "neutral" (3 points) and "comparatively agree" (4 points).

\subsection{Statistics}

The test of the third-person effect perception of online commercials is the test for Hypothesis 1, where for online commercials, there is a third-person effect; that is, people tend to think that online commercials affect others more than themselves. It mainly compares the mean value of the influence of online commercial advertising on oneself and that on others. A paired sample T-test has been adopted (Table 1).

Table 1. Paired sample T-test of the third-person effect perception in online commercial advertising

\begin{tabular}{lcccccc}
\hline & Difference & Standard deviation & Standard error & $\mathrm{t}$ & $\mathrm{Df}$ & Sig \\
\hline Self-other adults & -.44928 & .89217 & .03797 & -11.831 & 553 & .000 \\
Self-minor & -.76492 & 1.41514 & .06018 & -12.711 & 553 & .000 \\
\hline
\end{tabular}

From the comparison of the averages, the average value of the respondents' assessment of "the influence of online commercial advertisements on themselves" was 2.29, the average value of "the influence of online commercial advertisements on other adults" was 2.74 , and the average value of "the influence of online commercial advertisements on minors" was 3.06. According to the results from the paired sample T-test, it can be appreciated that the respondents believe that the influence of online commercial advertising on other adults is greater than the influence on other themselves; $\mathrm{T}(554)=-11.83$ $(\mathrm{P}<.001)$, the difference reached a significant level; the respondents also believe that the influence of online commercial advertising on minors is greater than the influence on themselves, $\mathrm{T}(554)=-12.71$ ( $\mathrm{P}$ $<.001$ ), the difference reached a significant level. According to the above analysis, Hypothesis $\mathbf{1}$ is confirmed; that is, for online commercial advertising, there is a third-person effect, in which people tend to think that the influence of online commercial advertisements on others is greater than that on themselves.

The relationship between social distance and the third-person effect perception has been verified. The results showed that for the respondents, online commercial advertising has the greatest impact on minors, followed by other adults, and has the least impact on themselves. It can be seen that the effect of the third person was more obvious along the following sequence: the social distance between themselves and other adults and then minors. 


\subsection{Analysis of the influencing factors of the third-person effect perception}

In determining the influencing factors of the third-person effect perception; that is, in verifying Hypothesis 2, correlation analysis was used. Since gender, professional background, media contact type, and the purpose of media use are not continuous variables, these variables are treated as dummy variables for coding before correlation analysis.

\subsubsection{Correlation analysis}

The correlation analysis between variables such as gender, professional background, media use, information variables, personal characteristics, and third-person effect perception using Pearson correlation analysis, the correlation analysis matrix is as shown in Table 2.

Table 2. Correlation analysis of the third-person effect perception in online commercial advertising

\begin{tabular}{|c|c|c|}
\hline & Third-person effect perception of other adults & Third-person effect perception of minors \\
\hline \multicolumn{3}{|l|}{ Gender } \\
\hline Pearson correlation & 0.013 & -0.065 \\
\hline Sig. (2-tailed) & 0.757 & 0.128 \\
\hline \multicolumn{3}{|c|}{ Professional background } \\
\hline Pearson correlation & -0.035 & $-.133 * *$ \\
\hline Sig. (2-tailed) & 0.406 & 0.002 \\
\hline \multicolumn{3}{|c|}{ Types of media contact } \\
\hline Pearson correlation & -0.036 & -0.002 \\
\hline Sig. (2-tailed) & 0.399 & 0.965 \\
\hline \multicolumn{3}{|l|}{ Purpose of media use } \\
\hline Pearson correlation & 0.078 & 0.06 \\
\hline Sig. (2-tailed) & 0.066 & 0.158 \\
\hline \multicolumn{3}{|l|}{ Internet age } \\
\hline Pearson correlation & -0.034 & 0.044 \\
\hline Sig. (2-tailed) & 0.427 & 0.304 \\
\hline \multicolumn{3}{|c|}{ Average daily online time } \\
\hline Pearson correlation & -0.069 & -0.047 \\
\hline Sig. (2-tailed) & 0.104 & 0.266 \\
\hline \multicolumn{3}{|l|}{ Media exposure } \\
\hline Pearson correlation & 0.003 & 0.042 \\
\hline Sig. (2-tailed) & 0.952 & 0.325 \\
\hline \multicolumn{3}{|l|}{ Social recognition } \\
\hline Pearson Correlation & -0.026 & $-139 * *$ \\
\hline Sig. (2-tailed) & 0.545 & 0.001 \\
\hline \multicolumn{3}{|l|}{ Credibility } \\
\hline Pearson correlation & -0.071 & $-231 * *$ \\
\hline Sig. (2-tailed) & 0.097 & 0 \\
\hline \multicolumn{3}{|l|}{ Network performance } \\
\hline Pearson correlation & -0.043 & 0 \\
\hline Sig. (2-tailed) & 0.317 & 0.983 \\
\hline
\end{tabular}


Third-person effect perception of other adults Third-person effect perception of minors

\begin{tabular}{lcc}
\hline Pre-existing attitude & & $.094^{*}$ \\
Pearson correlation & 0.025 & 0.028 \\
Sig. (2-tailed) & 0.564 & $.195^{* *}$ \\
\hline Overall evaluation & & 0 \\
Pearson correlation & 0.046 & 0 \\
Sig. (2-tailed) & 0.277 & \\
\hline
\end{tabular}

Note: The code description for gender: male $=1$, female $=0$; professional background: science and engineering major $=1$, nonscience and engineering major $=0$; type of media contact: internet $=1$, others $=0$; purpose of media use: entertainment and relaxation $=1$, non-entertainment or relaxation $=0$. $* *$ reflects that correlation is significant at the 0.01 level $(2$-tailed $)$, while $*$ reflects that correlation is significant at the 0.05 level (2-tailed).

The results of the above analysis are as follows:

(1) There is no significant correlation between gender and the third-person effect perception of other adults; in addition, there is also significant correlation between gender and the third-person effect perception of minors.

(2) There is no significant correlation between the professional background and the perception of the third-person effect perception of other adults. However, there is a significant correlation between the professional background and the third-person effect perception of minors, $\mathrm{r}=-0.133, P<0.01$.

(3) There is no significant correlation between the type of media contact and the third-person effect perception of other adults.

(4) There is no significant correlation between the purpose of media use and the third-person effect perception of other adults; the same applies for the third-person effect perception of minors.

(5) There are no significant correlations between the various variables used by the media, including internet age, average daily online time, and media exposure, with the third-person effect perception.

(6) The correlation between internet efficacy and the third-person effect perception is not significant.

(7) There is no significant correlation between social recognition of online commercial advertising and the third-person effect perception of other adults. Social recognition of online commercial advertising has a significant negative correlation with the third-person effect perception of minors, $\mathrm{r}=-0.139, P<0.01$, reflecting that when the respondents' social recognition of online commercials is low, the more likely they would think that the influence of online commercials on minors is greater than the influence on themselves; the cognitive deviation of the third-person effect is more obvious comparing themselves and minors.

(8) There is no significant correlation between the credibility of online commercial advertising and the third-person effect perception of other adults. The credibility of online commercials is significantly negatively correlated with the third-person effect perception of minors, indicating that the lower the respondents' evaluation of the credibility of online commercials, the more likely they are to think that the influence of online commercials on minors is greater than the influence on themselves and the third-person effect of minors is greater.

(9) The audience's pre-existing attitude toward online commercial advertising is not significantly related to the third-person effect perception of other adults, but it has a significant positive 
correlation with the third-person effect perception of minors, $\mathrm{r}=0.195, P<0.01$, reflecting that the more opposed the respondents' pre-existing attitude is toward online commercial advertising, the more likely they are to think that the influence on minors is greater than the influence on themselves.

(10) The audience's overall evaluation of online commercial advertising is not significantly correlated with the third-person effect perception of other adults, but there is a significant positive correlation with the third-person effect perception of minors, $r=0.195, P<0.01$. This indicates that the more negative the respondents' overall rating of online commercial advertisements, the more likely they are to think that online commercial advertisements have greater influence on minors than on themselves, and the third-person effect of minors is more obvious.

(11) The correlation between self-esteem and the third-person effect perception of other adults is significantly positively correlated, $\mathrm{r}=0.104, P<0.05$, reflecting that the higher the degree of selfesteem, the more inclined one would think that the influence of commercial advertising on other adults is greater than the influence on oneself and the more obvious the third-person effect of other adults. Although the correlation analysis shows that the correlation between self-esteem and the third-person effect perception of minors is not significant, considering that the influence of selfesteem on the third-person effect perception is affected by other variables, it controls other variables. In the case of related variables, net correlation analysis was used to analyze the relationship between self-esteem and the third-person effect perception, in which the partial correlation coefficient, $\mathrm{r}=$ $0.102, P<0.05$, reflecting that self-esteem and the three-person effect perception is significantly correlated.

\subsubsection{Regression analysis}

From the analysis, it can be seen that there are several variables that are significantly related to the thirdperson effect perception of minors, including the professional background, the social recognition of online commercial advertisements, the credibility of online commercial advertisements, the pre-existing attitude of the audience, as well as the audience's overall evaluation and self-esteem. The cognition of the thirdperson effect on minors is assumed as the dependent variable, $\mathrm{Y}$, and the professional background of the respondent is assumed as the independent variables, $\mathrm{X} 1, \mathrm{X} 2, \mathrm{X} 3, \mathrm{X} 4, \mathrm{X} 5$, and $\mathrm{X} 6$; the regression equation is the established as follows:

$$
Y=b(0)+b(1) * \times 1+b(2) * \times 2+b(3) * \times 3+b(4) * \times 4+b(5) * \times 5+b(6) * \times 6
$$

Using multiple regression analysis, the correlations between the independent variables and the dependent variable have been analyzed to determine the main and secondary influencing factors. The multiple regression analysis adopted the forced entry method, where all the variables are directly forced into the regression model.

Table 3. Regression analysis of factors influencing the third-party perception of online commercial advertising

\begin{tabular}{ccccc}
\hline $\mathrm{R}$ & $\mathrm{R}$-squared & Adjusted R-squared & Estimated standard error & Autocorrelation coefficient \\
\hline $.309^{\mathrm{a}}$ & .095 & .085 & 1.35251 & 1.885 \\
\hline
\end{tabular}

From the results of the regression analysis, the correlation coefficient, $\mathrm{R}$, is 0.309 , and the judgment coefficient, $\mathrm{R}^{2}$, is 0.095 , reflecting that the 6 independent variables can explain $9.5 \%$ of the variation of the 
dependent variable; thus, the explanatory power of the regression model is $9.5 \%$ (Table 3 ).

Table 4. Analysis of variance within the regression model

\begin{tabular}{cccccc}
\hline Model & Sum of square & Degree of freedom & Mean square error & F & Sig. \\
\hline Regression & 105.412 & 6 & 17.569 & 9.604 & \\
Residual & 1000.612 & 547 & 1.829 & & \\
Total & 1106.023 & 553 & & & \\
\hline
\end{tabular}

From the analysis of variance within the regression model, the result from F-test, which was used to determine the significance of the regression equation, showed that $\mathrm{F}$ value is $9.332, P<0.00$, indicating that the regression is extremely significant; that is, the regression equation is meaningful (Table 4). However, the explanatory power of the regression model is not strong, and it can only explain $9.5 \%$ of the variation of the dependent variable (the effect of online commercial advertising on the third-person perception of minors). The most significant influencing variables are credibility of online commercials, overall evaluation of online commercials, and self-esteem, among which credibility of online commercials is the most powerful predictor, followed by the overall evaluation of online commercial advertising, and then, self-esteem.

Using regression analysis, variables such as gender, professional background, media use, information variables, and personal characteristics are included in the regression analysis as independent variables. The results of the regression analysis showed that the significant influencing factors of the expectations of selfeffect include media exposure of online commercial advertising (Beta $=0.098, \mathrm{P}<0.05$ ) and network performance (Beta $=-0.095, P<0,05$ ). Among them, the credibility of online commercial advertising is the most powerful influencing factor, indicating that the higher the credibility of online commercials, the stronger the audiences' expectations of their own effects, followed by exposure to online commercials and network performance.

The results also showed that the significant influencing factors of the expected effects on other adults include media exposure of online commercial advertising (Beta $=0.105, P<0.05$ ) and the credibility of online commercial advertisements (Beta $=0.186, \mathrm{P}<0.001)$. Among them, the credibility of online commercials is the most powerful influencing factor, followed by media exposure of online commercials. Moreover, the results also showed that the most significant influencing factor of the expected effect on minors is the media exposure of online commercial advertising (Beta $=0.112, \mathrm{P}<0.05)$. This indicates that the more frequent the audience's come into contact with online commercial advertisements, the stronger the expectation of the effect on minors.

Therefore, what factors can predict the effect of oneself and the effect on others? The results from the regression analysis showed that the credibility of online commercial advertising, media exposure of online commercial advertising, and network performance are significant predictors of the expectations of selfeffect. The credibility of online commercials and the media exposure to online commercials are significant predictors of the expected effects on other adults; media exposure to commercial advertisements is a significant predictor to the expectations of the effect on minors.

\section{Analysis and discussion}

The main findings of this research not only confirmed the third-person effect of online commercial advertising under the network environment for the first time, but also tested the third-person effect perception and support for the possible influencing factors that limit online commercial advertising, further verifying previous research hypotheses, but with some inconsistent results, which would further promote 
the research on the third-person effect in the network environment.

The findings of this study have brought a certain degree of inspiration for the formulation of online commercial advertising marketing communication strategies and the management of online commercials. Using relevant factors such as the credibility of online commercial advertisements and media exposure to enhance the audiences' expectations of the effect of online commercial advertisements on themselves is a problem that online marketing communicators should pay attention to. Identifying the reasons and influencing factors of the audiences' support for restricting online commercial advertisements and strengthening the management norms of online commercial advertisements would help create a good communication environment for online commercial advertisements.

\section{Funding}

This study was supported by the Research on Cultivation Strategy of Double-Qualified Teachers in Guangdong Application-Oriented Universities - Taking Guangzhou Huashang College as the Analysis Sample (Number: 2021GXJK429) and the Intelligent Marketing from the Perspective of Social Communication (Number: 2019WQNCX167).

\section{Disclosure statement}

The authors declare that there is no conflict of interest.

\section{References}

[1] Davison WP, 1983, The Third-Person Effect in Communication. Public Opinion Quarterly, 47(1): 115.

[2] Gunther AC, 1991, What We Think Others Think: Cause and Consequence in the Third-Person Effect. Communication Research, 18(3): 355-372.

[3] Perloff RM, 1993, Third Person Effect Research 1983-1992: A Review and Synthesis. International Journal of Public Opinion Research, 5(2): 167-184.

[4] Atwood LE, 1994, Illusions of Media Power: The Third-Person Effect. Journalism Quarterly, 71(2): 269-281.

[5] Eveland WP, McLeod DM, 1999, The Effect of Social Desirability on Perceived Media Impact: Implications for Third-Person Perceptions. International Journal of Public Opinion Research, 11(4): 315-333.

[6] Eastin MS, LaRose ER, 2000, Internet Self-Efficacy and the Psychology of the Digital Divide. Journal of Computer-Mediated Communication, 6(1): 0-0. 